\title{
Altered amygdala resting-state functional connectivity in post-traumatic stress disorder
}

\author{
Christine A. Rabinak ${ }^{1,2}$, Mike Angstadt ${ }^{2}$, Robert C. Welsh ${ }^{3}$, Amy E. Kenndy ${ }^{1}$, Mark Lyubkin ${ }^{1,2}$, Brian Martis ${ }^{1,2}$ \\ and K. Luan Phan ${ }^{1,2,4 *}$
}

${ }^{1}$ Mental Health Service, Veteran's Administration Ann Arbor Healthcare System, Ann Arbor, MI, USA

${ }^{2}$ Department of Psychiatry, University of Michigan, Ann Arbor, MI, USA

${ }^{3}$ Department of Radiology, University of Michigan, Ann Arbor, MI, USA

${ }^{4}$ Neuroscience Program, University of Michigan, Ann Arbor, MI, USA

\section{Edited by:}

Ben Harrison, The University of Melbourne, Australia

Reviewed by:

Leonardo Fontenelle, Institute of Psychiatry at the Federal University of Rio de Janeiro, Brazil

Narcis Cardoner, Bellvitge University

Hospital, Barcelona University, Spain

*Correspondence:

K. Luan Phan, Department of Psychiatry, University of Michigan, Rachel Upjohn Building, Room 2751, 4250 Plymouth Road, Ann Arbor, MI 48109-2700, USA.

e-mail: luan@umich.edu
Post-traumatic stress disorder (PTSD) is often characterized by aberrant amygdala activation and functional abnormalities in corticolimbic circuitry, as elucidated by functional neuroimaging. These "activation" studies have primarily relied on tasks designed to induce region-specific, and task-dependent brain responses in limbic (e.g., amygdala) and paralimbic brain areas through the use of aversive evocative probes. It remains unknown if these corticolimbic circuit abnormalities exist at baseline or "at rest," in the absence of fear/anxiety-related provocation and outside the context of task demands. Therefore the primary aim of the present experiment was to investigate aberrant amygdala functional connectivity patterns in combat-related PTSD patients during resting-state. Seventeen Operation Enduring Freedom/Operation Iraqi Freedom (OEF/OIF) veterans with combatrelated PTSD (PTSD group) and 17 combat-exposed OEF/OIF veterans without PTSD [combat-exposed control (CEC) group] underwent an 8-min resting-state functional magnetic resonance imaging scan. Using an anatomically derived amygdala "seed" region we observed stronger functional coupling between the amygdala and insula in the PTSD group compared to the CEC group, but did not find group differences in amygdala-prefrontal connectivity. These findings suggest that the aberrant amygdala and insula activation to fear-evocative probes previously characterized in PTSD may be driven by an underlying enhanced connectivity between the amygdala, a region known for perceiving threat and generating fear responses, and the insula, a region known for processing the meaning and prediction of aversive bodily states. This enhanced amygdala-insula connectivity may reflect an exaggerated, pervasive state of arousal that exists outside the presence of an overt actual threat/danger. Studying amygdala functional connectivity "at rest" extends our understanding of the pathophysiology of PTSD.

Keywords: amygdala, resting-state, functional magnetic resonance imaging, post-traumatic stress disorder

\section{INTRODUCTION}

Post-traumatic stress disorder (PTSD) is characterized by various altered emotional responses as a result of trauma exposure (e.g., combat, assault, and disasters). Patients with PTSD not only experience intense negative emotional reactions when reminded of their trauma but also report exaggerated arousal (poor sleep, restlessness, hypervigilance), anhedonia, social withdrawal, and decreased emotional expressivity, referred to as "emotional numbing." Characterizing the neural basis of these diverse, distorted emotional responses poses a major challenge to contemporary psychiatric research. Functional neuroimaging techniques have focused primarily on the study of brain function related to fear perception and response, and have consistently implicated aberrant amygdala reactivity to fear-relevant probes and other abnormalities in a broad aberrant amygdala-linked circuitry involving the medial prefrontal cortex (mPFC), insula, anterior cingulate cortex (ACC), and hippocampus (Rauch and Shin, 1997; Pitman et al., 2001; Nemeroff et al., 2006; Rauch et al., 2006; Etkin and Wager,
2007; Liberzon and Sripada, 2008; Shin, 2009; Shin and Liberzon, 2010). Together these interconnected regions form a disrupted functional network thought to be responsible for impaired regulation of fear responses, enhanced attention to threat-related stimuli, and biased memory for adverse events (Shin, 2009). Anxiety disorders, such as PTSD, are believed to manifest from dysfunction in a complex integrated functional network, largely, between cortical and limbic regions (Gilboa et al., 2004; Lanius et al., 2005; Simmons et al., 2008; Bluhm et al., 2009; Shaw et al., 2009; Daniels et al., 2010). Some studies have begun to examine these brain circuits and region-to-region interactions, by measuring the extent to which activity in one region is correlated with activity in another during a particular task. Although these dysfunctional networks have been implicated in mediating several characteristics of PTSD, such as, hyperarousal, abnormal reactivity to emotional stimuli, and avoidance of emotionally distressing memories (Nemeroff et al., 2006; Shin and Liberzon, 2010), little is known about how these regions may interact dynamically within individual subjects. 
Some clues exist from anatomical and functional studies that these brain regions may indeed form a network responsible for emotion processing. Tracer studies in non-human primates (Amaral and Price, 1984; Saunders et al., 1988; Barbas and De Olmos, 1990; Stefanacci et al., 1996; Ghashghaei and Barbas, 2002; Ghashghaei et al., 2007; Freese and Amaral, 2009) and, more recently, diffusion tensor imaging studies in humans (Croxson et al., 2005; Johansen-Berg et al., 2008; Bracht et al., 2009) have identified robust bidirectional projections between the amygdala and the mPFC, rostral ACC (rACC), insula, and hippocampus. Consistent with known anatomical connections, several studies that have examined functional connectivity of the amygdala have found significant co-activation and/or functionally correlated activation of the amygdala and the mPFC, insula, hippocampus, and rACC (Phan et al., 2002; Wager et al., 2003, 2008; Stein et al., 2007a; Kober et al., 2008; Etkin et al., 2009; Roy et al., 2009). It is well established that negatively valenced emotional stimuli activate the amygdala, which mediates subjective and attentional-vigilance aspects of threat processing (Liberzon et al., 1999; Phan et al., 2002, 2004; Liberzon and Phan, 2003; Taylor et al., 2003; Wager et al., 2003; Etkin and Wager, 2007; Kober et al., 2008; Liberzon and Sripada, 2008; Etkin, 2009; Shin and Liberzon, 2010). Similarly, insula activity also increases in response to emotionally aversive stimuli that evoke visceral or somatic sensations (Simmons et al., 2004). Increased amygdala and insula activation during fear conditioning have been shown to be reliably associated with one another (Etkin and Wager, 2007). Amygdala activity is decreased in response to suppression of negative affect via reappraisal and during inhibition of conditioned fear responses as a result of increased activation in the mPFC and rACC, which exert top-down inhibitory influences on amygdala reactivity to fear and threat (Ochsner et al., 2002; Taylor et al., 2003; Phelps et al., 2004; Etkin et al., 2006, 2011; Urry et al., 2006; Delgado et al., 2008; Quirk and Mueller, 2008). The magnitude of task-dependent functional coupling between the amygdala and $\mathrm{mPFC} / \mathrm{rACC}$ has been shown to be negatively correlated with intensity of subjective reports of negative affect (Banks et al., 2007). Increased functional connectivity between the amygdala and the hippocampus has been attributed to the persistence of memories for emotionally arousing events (Hamann et al., 1999; Kilpatrick and Cahill, 2003; Phelps, 2004; Ritchey et al., 2008; Murty et al., 2011). Specifically, the hippocampus forms episodic representations of the emotional significance and interpretation of events, and influences amygdala activity when emotional stimuli are encountered (Phelps, 2004). These lines of convergent evidence suggests that how the amygdala interacts with other regions may mediate the control, or lack thereof, of fear perception and emotional arousal in humans.

Dysfunctions within discrete areas that form an amygdalaparalimbic/frontal network have been implicated in mediating several characteristics of PTSD, such as, hyperarousal, abnormal reactivity to emotional stimuli, and avoidance of emotionally distressing memories (Nemeroff et al., 2006; Shin and Liberzon, 2010). In particular, many studies have shown amygdala hyperactivity in PTSD in response to trauma-related imagery (Shin et al., 1997, 2004a), combat-related sounds or smells (Liberzon et al., 1999; Pissiota et al., 2002; Vermetten et al., 2007), traumarelated photographs or words (Hendler et al., 2003; Driessen et al.,
2004; Protopopescu et al., 2005; Morey et al., 2009), and fearful facial expressions (Rauch et al., 2000; Shin et al., 2005; Williams et al., 2006; Bryant et al., 2008). Exaggerated amygdala reactivity observed in PTSD has been posited to be a result of insufficient top-down regulation from the mPFC and ACC, consequently leading to hyperarousal and deficits in extinction as well as the inability to suppress enhanced fear perception or exaggerated fear responses to trauma-related stimuli (Rauch and Shin, 1997; Rauch et al., 1998; Pitman et al., 2001; Liberzon and Phan, 2003); for example, Shin et al. (2004a, 2005) have observed that exaggerated amygdala reactivity is negatively correlated with responses in the dorsal and ventral mPFC across individuals with PTSD. However, Gilboa et al. (2004) found little evidence for failure of inhibition of ACC over the amygdala in individuals with PTSD related to civilian trauma during symptom provocation and in fact found that amygdala activity significantly influenced ACC activity. Insula hyperactivity has been observed in PTSD patients and given its role in the experience (e.g., somatic sensation) of negative emotions and structural connectivity to amygdala (Augustine, 1996; Aggleton and Saunders, 2000; Freese and Amaral, 2009), the insula may be working in concert with aberrant amygdala responses (Bremner et al., 2003, 2005; Lanius et al., 2007; Vermetten et al., 2007; Lindauer et al., 2008; Simmons et al., 2008; Werner et al., 2009; Whalley et al., 2009). Although less commonly implicated, abnormal hippocampal function, and diminished hippocampal volumes in PTSD patients have been associated with deficits in contextual processing, as well as memory impairments, and neuroendocrine dysregulation (Bremner et al., 1999, 2003; Bonne et al., 2001; Shin et al., 2004a,b, 2006; Werner et al., 2009).

Recently these functional connectivity techniques have been applied to the study of corticolimbic circuitry abnormalities at baseline or "at rest" (resting-state functional connectivity). Studies of functional interconnectivity of brain regions derived from "resting-state" scans provides insight into the relationship of spontaneous brain activity between brain regions without being confounded by task influences on activation and has even been shown to reflect structural connectivity between brain regions (Greicius et al., 2009; van den Heuvel et al., 2009). In healthy humans resting-state functional connectivity of the amygdala has revealed patterns of connectivity consistent with task-based connectivity patterns (Stein et al., 2007a; Roy et al., 2009). Moreover, resting-state functional connectivity has been a useful tool for identifying abnormalities in the functional organization of brain systems in several anxiety and mood disorders (Greicius, 2008). However, little is known about what abnormalities, if any, in amygdala connectivity exist at rest in PTSD. Therefore the primary aim of the present experiment was to investigate aberrant amygdala functional connectivity patterns in returning Operation Enduring Freedom/Operation Iraqi Freedom (OEF/OIF) veterans with combat-related PTSD (PTSD group) and combat-exposed OEF/OIF veterans without PTSD [combat-exposed control (CEC) group] during resting-state. We hypothesized that amygdala connectivity to the ACC, mPFC, insula, and hippocampus would differentiate the PTSD group from the CEC group. If observed, such findings would extend our understanding of the pathophysiology of PTSD by identifying a disturbed network that exists 
outside of the presence of an overt threat/danger or in the absence of stimulus or task-induced negative emotional processing.

\section{MATERIALS AND METHODS PARTICIPANTS}

Thirty-four, right-handed, male veterans returning from OEF/OIF with documented exposure to combat-related trauma participated in this study. Based on the DSM-IV (APA, 1994), 17 participants met criteria for current PTSD (PTSD group; age: $30.12 \pm 7.70$ years; Caucasian $=16$; Hispanic or Latino $=1)$ and the other 17 participants were combat-exposed matched controls without PTSD (CEC group; age: $33.71 \pm 9.12$; Caucasian $=16$; Asian $=1)$. Psychiatric diagnoses were established via the Structured Clinical Interview for DSM-IV (First et al., 1996). Additional standardized clinical instruments including the Clinician Administered PTSD Scale (CAPS; Blake et al., 1995), the PTSD Checklist: Military (PCL-M; Blanchard et al., 1996), the Combat Exposure Scale (CES; Keane et al., 1989), the Hamilton Depression Inventory (HAM-D; Williams, 1988), and the Beck Depression Inventory (BDI-II; Beck et al., 1996) were administered to quantitatively characterize PTSD symptoms, severity of trauma exposure, and depression.

Table 1 shows the participant's demographic and clinical characteristics. Relative to the CEC group, the PTSD group had significantly higher scores on the CAPS, PCL-M, and HAM-D and BDIII. Of note, the groups did not differ in severity of trauma exposure. Some of the PTSD patients had current psychiatric co-morbidity ( $n=2$ with current major depressive disorder; $n=2$ with current alcohol abuse) or had a past co-morbidity more than 6 months ago ( $n=1$ had major depressive disorder; $n=4$ had alcohol abuse, one of whom also had past opioid abuse; $n=1$ had alcohol dependence in full sustained remission) at the time of scanning. In addition, some PTSD patients had a history of psychotropic medication usage ( $n=8$ had taken an selective serotonin reuptake inhibitor, one of whom had also taken a norepinephrine-dopamine reuptake inhibitor; $n=1$ had taken a tri-cyclic antidepressant; $n=2$ had taken a serotonin antagonist-reuptake inhibitor), but none of the PTSD patients were currently taking any psychotropic medications at the time of scanning. All participants were free

Table 1 | Group demographic and clinical characteristics.

\begin{tabular}{|c|c|c|c|c|}
\hline & \multicolumn{2}{|c|}{ Group mean $( \pm S D)$} & \multirow[t]{2}{*}{$t$ Value } & \multirow[t]{2}{*}{$p$ Value } \\
\hline & PTSD & CEC & & \\
\hline Age & $30.12(7.70)$ & $33.71(9.12)$ & -1.24 & 0.22 \\
\hline CAPS & $67.35(12.41)$ & $5.24(5.75)$ & 18.72 & $<0.001$ \\
\hline PCL-M & $54.59(9.78)$ & $25.06(7.34)$ & 9.96 & $<0.001$ \\
\hline BDI-II & $22.76(7.46)$ & $5.53(6.25)$ & 7.30 & $<0.001$ \\
\hline HAM-D & $10.18(3.75)$ & 2.18 (2.38) & 7.44 & $<0.001$ \\
\hline CES & $23.88(5.98)$ & $21.47(5.50)$ & 1.22 & 0.23 \\
\hline
\end{tabular}

PTSD, post-traumatic stress disorder; CEC, combat-exposed controls; CAPS, Clinician Administered PTSD Scale; PCL-M, PTSD Checklist: Military; BDI-II, Beck Depression Inventory; HAM-D, Hamilton Depression Inventory; CES, Combat Exposure Scale. of any clinically significant medical or neurologic condition that would affect brain blood flow/metabolism or function and/or task performance. None of the subjects had a positive urine toxicology screen at the time of scanning. All participants gave written informed consent after explanation of the experimental protocol, as approved by the VA Ann Arbor Healthcare System and University of Michigan Institutional Review Boards.

\section{FUNCTIONAL IMAGING ACQUISITION}

All participants underwent an 8-min resting-state fMRI scan in which they were instructed to fixate on a white crosshair that was centrally projected against a black background and let their mind wander without falling asleep. fMRI scanning was performed on a 3T GE Signa System (General Electric; Milwaukee, WI, USA) using a standard radiofrequency coil at the University of Michigan Functional MRI Laboratory. Whole-brain functional images (i.e., blood oxygenated level-dependent, BOLD) were collected from 43 axial, 3 -mm-thick slices using a $\mathrm{T}_{2}^{*}$-sensitive gradient echo reverse spiral acquisition sequence (repetition time, $2000 \mathrm{~ms}$; echo time, $30 \mathrm{~ms} ; 64 \times 64$ matrix; $220 \mathrm{~mm}$ field of view; flip angle, $90^{\circ}$ ), optimized to minimize susceptibility artifacts (signal loss) at the medial temporal lobe (including the amygdala; Stenger et al., 2000). Cardiac and respiratory cycles were recorded with MRI vendor supplied pulse-oximeter and respiratory belt for physiological corrections on resting-state data. $\mathrm{A}_{1}$-weighted anatomical image was collected in the same planes as the functional data, but with higher in-plane resolution $\left(1 \mathrm{~mm}^{2}, \mathrm{~T}_{1}\right.$-overlay) to aid in later co-registration. A high resolution, $\mathrm{T}_{1}$-weighted volumetric anatomical scan $\left(\mathrm{T}_{1}\right.$-SPGR; three-dimensional spoiled gradient echo) was also acquired for precise anatomical localization and normalization.

\section{FUNCTIONAL IMAGING ANALYSIS}

Data from 32 participants $(\mathrm{CEC}=17 ; \mathrm{PTSD}=15)$ met criteria for high quality and scan stability with minimum motion correction and were subsequently included in fMRI analyses $(<3 \mathrm{~mm}$ displacement in any one direction; two PTSD patients were excluded for poor data quality due to excessive head movement). The first four volumes were discarded to allow for $T_{1}$ equilibration effects. Functional data were processed and analyzed using Statistical Parametric Mapping software (SPM8; Wellcome Trust Centre for Neuroimaging, London ${ }^{1}$ ) using similar methods previously published from our lab (Jelsone-Swain et al., 2010). Images were corrected for physiological signal fluctuations using a custom code written in MATLAB (MathWorks, Natick, MA, USA; Noll et al., 1991). Slice timing and movement correction was done to the time-series data using SPM8. Each participant's $\mathrm{T}_{1}$-overlay was co-registered to the time-series data and the $\mathrm{T}_{1}$-SPGR was then coregistered to the co-registered $\mathrm{T}_{1}$-overlay image. The co-registered $\mathrm{T}_{1}$-SPGR was then segmented into gray matter, white matter, and cerebrospinal fluid (CSF) and normalized to Montreal Neurological Institute (MNI) space using VBM8 toolbox of SPM8 and the resulting normalization matrix was applied to the time-series data. These normalized time-series data were subsequently re-sampled

${ }^{1}$ www.fil.ion.ucl.ac.uk/spm 
to $2 \mathrm{~mm}^{3}$ voxels and smoothed with an $8-\mathrm{mm}$ Gaussian kernel to minimize noise and effects due to residual differences in functional and gyral anatomy during inter-subject averaging. Then the resulting white matter and CSF segments were further defined using a custom algorithm previously described (Welsh et al., 2007). Each voxel's time-series was detrended to correct for linear drift over time. Nine nuisance covariates (time-series predictors for global signal, white matter, CSF, and the six movement parameters, including the first derivative, obtained during realignment to account for motion-related effects in BOLD) were sequentially regressed from the time-series. The resulting time-series were then band-passed filtered between the frequencies of 0.01 and $0.10-\mathrm{Hz}$ to limit the analysis to resting-state frequencies of interest.

To determine amygdala connectivity during resting-state, seed regions in the left and right amygdala were defined by an anatomically based amygdala mask in each hemisphere (from MAsk of region of interest analysis software, MARINA; Tzourio-Mazoyer et al., 2002; Walter et al., 2003). We then extracted the averaged time course from these seed regions in each participant's data and calculated correlation coefficients between these average time courses and all other voxels of the brain resulting in an $r$-image for amygdala connectivity. The resulting correlation coefficients were then transformed into $Z$-scores using a Fisher $r$-to- $Z$ transformation and the resulting $Z$ images were analyzed at the second level in a random-effects statistical model. Two-tailed independent samples $t$ tests were used to identify areas of the brain that exhibited activity that covaried with the amygdala differentially during resting-state between the two groups (PTSD > CEC; CEC > PTSD). Significant activations were identified with a whole-brain voxel-wise threshold of $p<0.005$ with a minimum cluster extent of $>387$ contiguous voxels $\left(3096 \mathrm{~mm}^{3}\right)$, to correct for multiple comparisons at a corrected $p<0.05$ calculated using Monte-Carlo simulations (AFNI 3dClustSim ${ }^{2}$ ). Previous studies interested in differences in brain connectivity between patients with PTSD and traumaexposed controls without PTSD have used similar significance

${ }^{2}$ http://afni.nimh.nih.gov/pub/dist/doc/program_help/3dClustSim.html thresholding approaches to balance Type I and II error rates (Yin et al., 2011a,b). To clarify the signal direction, variance, and specificity of differences in strength of connectivity between the CEC and PTSD groups during resting-state, we extracted individual subject's $Z$-score values from activated voxels that fell within an anatomically based mask for each a priori region from the between-group contrast (PTSD > CEC; Tzourio-Mazoyer et al., 2002; Walter et al., 2003). Of note, we did not conduct statistical tests on these measures, as they were defined from significant activations resulting from whole-brain maps of group differences in connectivity.

\section{RESULTS}

Across the entire brain, we observed a discretely localized difference in amygdala connectivity pattern between groups. From the right amygdala anatomical "seed" region, we observed that PTSD patients exhibited stronger connectivity with the insula than CEC subjects (MNI peak: $[38,-18,-2], Z$-score $=4.29$, volume $=440$ voxels; Figure 1); this pattern was not detected from the left amygdala seed. Follow-up ROI analyses on the extracted $Z$-scores of the strength of connectivity from the insula revealed that both groups exhibited positive amygdala-insula coupling, however, the extent of connectivity between the amygdala and insula was greater in the PTSD group than the CEC group (Figure 1). To explore the clinical relevance of the observed amygdala-insula connectivity abnormalities, we performed correlational analyses between the extracted values of the strength of connectivity and PTSD symptom severity measures (CAPS, BDI-II, PCL-M, and HAM-D) but did not observe any significant correlations (all $p s>0.05$, corrected for multiple comparisons). Of note, we did not observe group differences in any other a priori areas that we predicted, such as the ACC, mPFC, and hippocampus in relation to amygdala connectivity at rest.

\section{DISCUSSION}

This is the first study to our knowledge that examines intrinsic amygdala functional connectivity patterns during rest in returning OEF/OIF veterans with combat-related PTSD compared to a

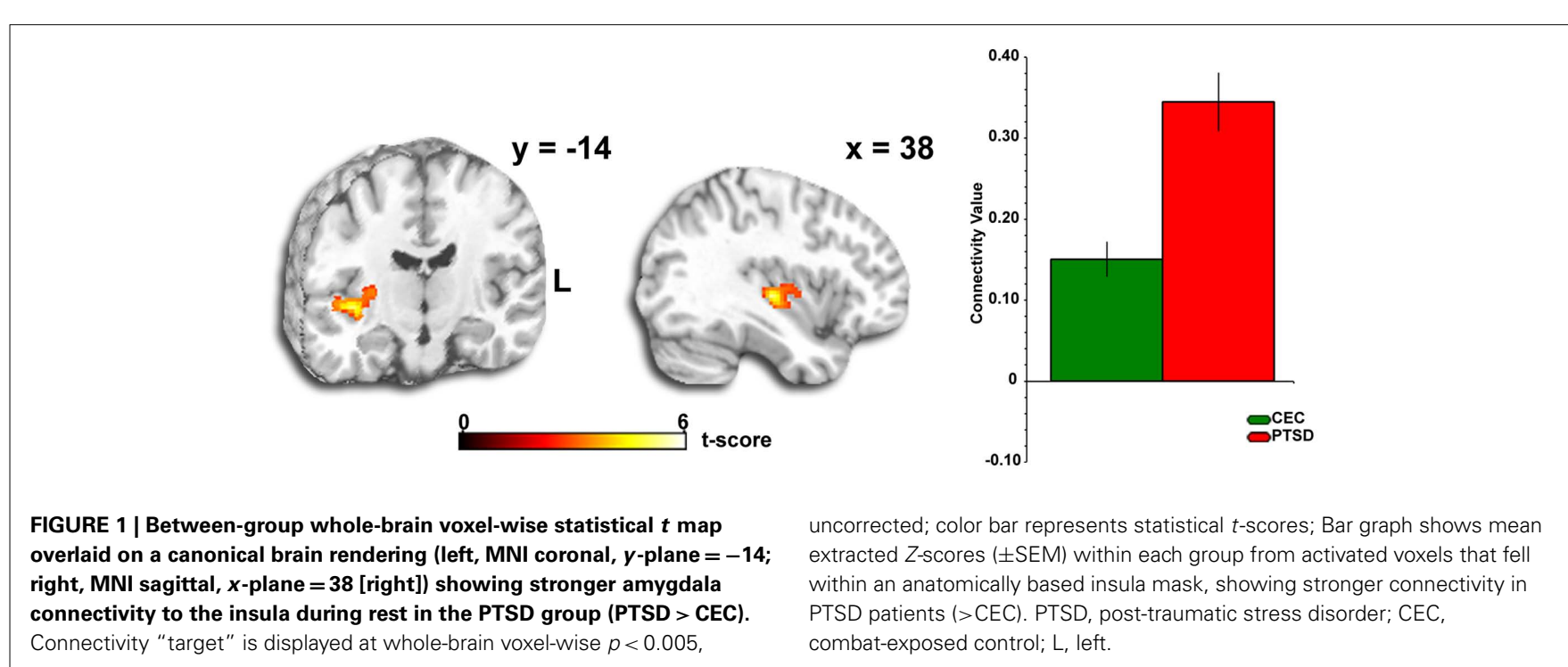


group of OEF/OIF veterans with combat exposure, but without PTSD. We found stronger amygdala-insula resting-state functional connectivity in the PTSD group compared to the CEC group. Of note, this connectivity pattern was from the right amygdala "seed" and was not shown from the left amygdala. Although we did not make an a priori prediction about lateralization of amygdala resting-state connectivity several findings of amygdala hyperactivity in PTSD and correlations between PTSD symptom severity and amygdala activity have been right-sided (Rauch et al., 1996, 2000; Pissiota et al., 2002; Fredrikson and Furmark, 2003; Driessen et al., 2004; Shin et al., 2004a). Contrary to our original hypothesis we did not observe any significant differences in amygdala connectivity to any other a priori regions (mPFC, ACC, hippocampus) in the PTSD group compared to the CEC group at rest. This is a notable negative finding and requires replication; however, we acknowledge that the absence of differences in amygdalafrontal or amygdala-hippocampal connectivity between groups could have resulted from: (1) Our stringent, whole-brain correction for multiple comparisons to detect significance coupled with a small sample size may have led to false negatives and/or more subtle connectivity abnormalities; and/or (2) The restingstate task may be insensitive to detecting amygdala-prefrontal and amygdala-hippocampal connectivity abnormalities, which may require engagement by an overt task.

Both the amygdala and insula have been separately implicated in the pathophysiology of anxiety and PTSD (Rauch et al., 2000; Osuch et al., 2001; Pissiota et al., 2002; Shin et al., 2004a; Protopopescu et al., 2005; Nemeroff et al., 2006; Hopper et al., 2007; Carrion et al., 2008; Shin and Liberzon, 2010). The amygdala plays an important role in the subjective and attentional-vigilance aspects of threat processing, and thus abnormalities in amygdala activity may be associated with hyperarousal and hypervigilance to threat in PTSD (Etkin, 2009). Moreover, several studies have shown that the amygdala is hyperresponsive to both traumarelated (Rauch et al., 1996; Shin et al., 1997, 2004a; Liberzon et al., 1999; Pissiota et al., 2002; Hendler et al., 2003; Driessen et al., 2004; Protopopescu et al., 2005; Vermetten et al., 2007) and unrelated stimuli in PTSD (Rauch et al., 2000; Armony et al., 2005; Shin et al., 2005; Williams et al., 2006), amygdala activation is positively correlated with PTSD symptom severity (Rauch et al., 1996; Shin et al., 2004a; Armony et al., 2005; Protopopescu et al., 2005) and self-reported anxiety (Pissiota et al., 2002; Fredrikson and Furmark, 2003), and symptom reduction after treatment is associated with decreased amygdala activation (Felmingham et al., 2007). Likewise, PTSD patients display exaggerated insula activation during script-driven imagery (Lanius et al., 2007; Lindauer et al., 2008), fear conditioning and extinction (Bremner et al., 2005), the anticipation of negative images (Simmons et al., 2006), the retrieval of emotional or neutral stimuli (Bremner et al., 2003; Werner et al., 2009; Whalley et al., 2009), and aversive smells and painful stimuli (Vermetten et al., 2007) and is also positively correlated with PTSD symptom severity (Osuch et al., 2001; Hopper et al., 2007; Carrion et al., 2008). The insula controls evaluative, experiential, and expressive aspects of internal emotional states via visceral and somatic changes (e.g., autonomic "flight-or-fight" responses) evoked during presentations of aversive stimuli (Phan et al., 2002; Anderson et al., 2003; Dupont et al., 2003; Critchley et al., 2004; Simmons et al., 2004; Paulus and Stein, 2006) and it has been posited that the insula relays interoceptive information to the amygdala to help guide behavioral responses (Augustine, 1996; Craig, 2002; Simmons et al., 2004; Paulus and Stein, 2006). In fact, the insula provides some of the strongest cortical connections to the major output division of the amygdala responsible for generating fear responses to symptom-provoking stimuli (Augustine, 1996; Aggleton and Saunders, 2000; Freese and Amaral, 2009) and abnormalities in these structures has been suggested to underlie exaggerated fear responses and the persistence of traumatic memories (Shin and Liberzon, 2010), as well as anxiety proneness (Paulus and Stein, 2006; Simmons et al., 2006; Stein et al., 2007b). Furthermore, evidence from a recent study suggests that a functional network between the amygdala and insula mediates anxious anticipation of negative events and anxious individuals display exaggerated activity within this network during anticipation of aversive stimuli (Carlson et al., 2010). Individuals with PTSD display excess anticipation of negative events and because of this are preoccupied with studying their environment for possible threats (i.e., hypervigilance) and increased amygdala-insula functional coupling may be a mechanism supporting hypervigilance in patients with PTSD.

Besides the present study, others have investigated baseline connectivity patterns in patients with PTSD and observed abnormalities in functional connectivity within the default-mode network when compared to healthy controls (although sometimes inconsistent; Bluhm et al., 2009; Daniels et al., 2010; Lanius et al., 2010), not directly related to amygdala connectivity. Our study extends these findings to resting-state amygdala coupling within a corticolimbic network known to be dysfunctional during trauma-related anxiety provocation, emotionally based tasks, and evocative stimuli in PTSD patients. However, our study has some important limitations. First, our study only included males and therefore cannot be generalized to females. Second, the resting-state analysis of changes in amygdala-insula connectivity do not allow for inferences about directionality or causality, which await task-based path or dynamic causal analyses. In addition, we have interpreted our resting-state findings based on previous functional and structural imaging studies, however, research with converging methods (i.e., task-dependent and -independent fMRI, diffusion tensor imaging) are much needed to link connectivity at rest with brain structure and function. Lastly, the cross-sectional nature of our measurement does not allow us to ascertain whether enhanced amygdala-insula resting-state connectivity was present before the traumatic experience and if so, makes it a potential vulnerability maker for PTSD.

Despite these limitations, our findings demonstrate that alterations in these connectivity patterns in a network involved in emotional processing and regulation may be relevant to a brain model of PTSD that involves baseline abnormalities in amygdala-insula functional connectivity that exist even without task induction. These findings suggest that the aberrant amygdala and insula activation to fear-evocative probes previously characterized in PTSD may be driven by an underlying enhanced connectivity between amygdala, a region known for perceiving threat and generating fear responses, and the insula, a region known for processing the meaning and prediction of aversive bodily states. This enhanced 
amygdala-insula connectivity may reflect an exaggerated, pervasive state of arousal that exists outside the presence of an overt, actual threat/danger. Studying amygdala functional connectivity "at rest" extends our understanding of the pathophysiology of PTSD, and the current findings prompt further investigation in this emerging area of neuroimaging research.

\section{REFERENCES}

Aggleton, J. P., and Saunders, R. C. (2000). "The amygdala - what's happened in the last decade?" in The Amygdala: A Functional Analysis, 2nd Edn, ed. J. P. Aggleton (New York: Oxford Press), 1-30.

Amaral, D. G., and Price, J. L. (1984). Amygdalo-cortical projections in the monkey (Macaca fascicularis). J. Comp. Neurol. 230, 465-496.

Anderson, A. K., Christoff, K., Panitz, D., De Rosa, E., and Gabrieli, J. D. (2003). Neural correlates of the automatic processing of threat facial signals. J. Neurosci. 23, 5627-5633.

APA. (1994). Diagnostic and Statistical Manual of Psychiatry, 4th Edn. Washington, DC: American Psychiatric Publishing, Inc.

Armony, J. L., Corbo, V., Clement, M. H., and Brunet, A. (2005). Amygdala response in patients with acute PTSD to masked and unmasked emotional facial expressions. Am. J. Psychiatry 162, 1961-1963.

Augustine, J. R. (1996). Circuitry and functional aspects of the insular lobe in primates including humans. Brain Res. Brain Res. Rev. 22, 229-244.

Banks, S. J., Eddy, K. T., Angstadt, M., Nathan, P. J., and Phan, K. L. (2007). Amygdala-frontal connectivity during emotion regulation. Soc. Cogn. Affect. Neurosci. 2, 303-312.

Barbas, H., and De Olmos, J. (1990). Projections from the amygdala to basoventral and mediodorsal prefrontal regions in the rhesus monkey. J. Comp. Neurol. 300, 549-571.

Beck, A. T., Steer, R. A., Ball, R., and Ranieri, W. (1996). Comparison of Beck Depression Inventories-IA and -II in psychiatric outpatients. J. Pers. Assess. 67, 588-597.

Blake, D. D., Weathers, F. W., Nagy, L. M., Kaloupek, D. G., Gusman, F. D., Charney, D. S., and Keane, T. M. (1995). The development of a Clinician-Administered PTSD Scale. J. Trauma Stress 8, 75-90.

Blanchard, E. B., Jones-Alexander, J., Buckley, T. C., and Forneris, C. A. (1996). Psychometric properties of the PTSD Checklist (PCL). Behav. Res. Ther. 34, 669-673.

Bluhm, R. L., Williamson, P. C., Osuch, E. A., Frewen, P. A., Stevens, T. K.,
Boksman, K., Neufeld, R. W., Theberge, J., and Lanius, R. A. (2009) Alterations in default network connectivity in posttraumatic stress disorder related to early-life trauma. $J$. Psychiatry Neurosci. 34, 187-194.

Bonne, O., Brandes, D., Gilboa, A., Gomori, J. M., Shenton, M. E., Pitman, R. K., and Shalev, A. Y. (2001). Longitudinal MRI study of hippocampal volume in trauma survivors with PTSD. Am. J. Psychiatry 158, 1248-1251.

Bracht, T., Tuscher, O., Schnell, S., Kreher, B., Rusch, N., Glauche, V., Lieb, K., Ebert, D., Il'yasov, K. A., Hennig, J., Weiller, C., Van Elst, L. T., and Saur, D. (2009). Extraction of prefrontoamygdalar pathways by combining probability maps. Psychiatry Res. 174, 217-222.

Bremner, J. D., Narayan, M., Staib, L. H., Southwick, S. M., Mcglashan, T., and Charney, D. S. (1999). Neural correlates of memories of childhood sexual abuse in women with and without posttraumatic stress disorder. Am. J. Psychiatry 156, 1787-1795.

Bremner, J. D., Vermetten, E., Schmahl, C., Vaccarino, V., Vythilingam, M., Afzal, N., Grillon, C., and Charney, D. S. (2005). Positron emission tomographic imaging of neural correlates of a fear acquisition and extinction paradigm in women with childhood sexual-abuse-related post-traumatic stress disorder. Psychol. Med. 35, 791-806.

Bremner, J. D., Vythilingam, M., Vermetten, E., Southwick, S. M., Mcglashan, T., Staib, L. H., Soufer, R., and Charney, D. S. (2003). Neural correlates of declarative memory for emotionally valenced words in women with posttraumatic stress disorder related to early childhood sexual abuse. Biol. Psychiatry 53, 879-889.

Bryant, R. A., Kemp, A. H., Felmingham, K. L., Liddell, B., Olivieri, G., Peduto, A., Gordon, E., and Williams, L. M. (2008). Enhanced amygdala and medial prefrontal activation during nonconscious processing of fear in posttraumatic stress disorder: an fMRI study. Hum. Brain Mapp. 29, 517-523.

Carlson, J. M., Greenberg, T., Rubin, D., and Mujica-Parodi, L. R. (2010).

\section{ACKNOWLEDGMENTS}

This research was supported by the Veterans Affairs Merit Review Program Award (K. Luan Phan). The authors would like to acknowledge the OEF/OIF veterans for their participation in this research study and more importantly for their dedication and service to the United States of America.

Feeling anxious: anticipatory amygdalo-insular response predicts the feeling of anxious anticipation. Soc. Cogn. Affect. Neurosci. 6, 74-81.

Carrion, V. G., Garrett, A., Menon, V., Weems, C. F., and Reiss, A. L. (2008). Posttraumatic stress symptoms and brain function during a response-inhibition task: an fMRI study in youth. Depress. Anxiety 25, 514-526.

Craig, A. D. (2002). How do you feel? Interoception: the sense of the physiological condition of the body. Nat. Rev. Neurosci. 3, 655-666.

Critchley, H. D., Wiens, S., Rotshtein, P., Ohman, A., and Dolan, R. J. (2004). Neural systems supporting interoceptive awareness. Nat. Neurosci. 7, 189-195.

Croxson, P. L., Johansen-Berg, H., Behrens, T. E., Robson, M. D., Pinsk, M. A., Gross, C. G., Richter, W., Richter, M. C., Kastner, S., and Rushworth, M. F. (2005). Quantitative investigation of connections of the prefrontal cortex in the human and macaque using probabilistic diffusion tractography. J. Neurosci. 25 8854-8866.

Daniels, J. K., Mcfarlane, A. C., Bluhm, R. L., Moores, K. A., Clark, C. R., Shaw, M. E., Williamson, P. C., Densmore, M., and Lanius, R. A. (2010). Switching between executive and default mode networks in posttraumatic stress disorder: alterations in functional connectivity. J. Psychiatry Neurosci. 35, 258-266.

Delgado, M. R., Nearing, K. I., Ledoux, J. E., and Phelps, E. A. (2008). Neural circuitry underlying the regulation of conditioned fear and its relation to extinction. Neuron 59, 829-838.

Driessen, M., Beblo, T., Mertens, M. Piefke, M., Rullkoetter, N., SilvaSaavedra, A., Reddemann, L., Rau, H., Markowitsch, H. J., Wulff, H., Lange, W., and Woermann, F. G. (2004). Posttraumatic stress disorder and fMRI activation patterns of traumatic memory in patients with borderline personality disorder. Biol. Psychiatry 55, 603-611.

Dupont, S., Bouilleret, V., Hasboun, D. Semah, F., and Baulac, M. (2003). Functional anatomy of the insula: new insights from imaging. Surg. Radiol. Anat. 25, 113-119.
Etkin, A. (2009). Functional neuroanatomy of anxiety: a neural circuit perspective. Curr. Top. Behav. Neurosci. 2, 251-277.

Etkin, A., Egner, T., and Kalisch, R. (2011). Emotional processing in anterior cingulate and medial prefrontal cortex. Trends Cogn. Sci. (Regul. Ed.) 15, 85-93.

Etkin, A., Egner, T., Peraza, D. M., Kandel, E. R., and Hirsch, J. (2006). Resolving emotional conflict: a role for the rostral anterior cingulate cortex in modulating activity in the amygdala. Neuron 51, 871-882.

Etkin, A., Prater, K. E., Schatzberg, A. F., Menon, V., and Greicius, M. D. (2009). Disrupted amygdalar subregion functional connectivity and evidence of a compensatory network in generalized anxiety disorder. Arch. Gen. Psychiatry 66, 1361-1372.

Etkin, A., and Wager, T. D. (2007). Functional neuroimaging of anxiety: a meta-analysis of emotional processing in PTSD, social anxiety disorder, and specific phobia. Am. J. Psychiatry 164, 1476-1488.

Felmingham, K., Kemp, A., Williams, L., Das, P., Hughes, G., Peduto, A., and Bryant, R. (2007). Changes in anterior cingulate and amygdala after cognitive behavior therapy of posttraumatic stress disorder. Psychol. Sci. 18, 127-129.

First, M. B., Spitzer, R. L., Gibbon, M., and Williams, J. B. (1996). Structured Clinical Interview for the DSM-IV Axis I Disorders (SCID I/P, Version 2.0). New York: Biometrics Research Department, New York State Psychiatric Institute.

Fredrikson, M., and Furmark, T. (2003). Amygdaloid regional cerebral blood flow and subjective fear during symptom provocation in anxiety disorders. Ann. N. Y. Acad. Sci. 985 , 341-347.

Freese, J. L., and Amaral, D. G. (2009). "Neuroanatomy of the primate amygdala," in The Human Amygdala, eds P. J. Whalen and E. A. Phelps (New York: The Guilford Press), 3-42.

Ghashghaei, H. T., and Barbas, H. (2002). Pathways for emotion: interactions of prefrontal and anterior temporal pathways in the amygdala of the rhesus monkey. Neuroscience $115,1261-1279$. 
Ghashghaei, H. T., Hilgetag, C. C., and Barbas, H. (2007). Sequence of information processing for emotions based on the anatomic dialogue between prefrontal cortex and amygdala. Neuroimage 34, 905-923.

Gilboa, A., Shalev, A. Y., Laor, L., Lester, H., Louzoun, Y., Chisin, R., and Bonne, O. (2004). Functional connectivity of the prefrontal cortex and the amygdala in posttraumatic stress disorder. Biol. Psychiatry 55, 263-272.

Greicius, M. (2008). Resting-state functional connectivity in neuropsychiatric disorders. Curr. Opin. Neurol. $21,424-430$.

Greicius, M. D., Supekar, K., Menon, V., and Dougherty, R. F. (2009). Resting-state functional connectivity reflects structural connectivity in the default mode network. Cereb. Cortex 19, 72-78.

Hamann, S. B., Ely, T. D., Grafton, S. T., and Kilts, C. D. (1999). Amygdala activity related to enhanced memory for pleasant and aversive stimuli. Nat. Neurosci. 2, 289-293.

Hendler, T., Rotshtein, P., Yeshurun, Y., Weizmann, T., Kahn, I., BenBashat, D., Malach, R., and Bleich, A. (2003). Sensing the invisible: differential sensitivity of visual cortex and amygdala to traumatic context. Neuroimage 19, 587-600.

Hopper, J. W., Frewen, P. A., Van Der Kolk, B. A., and Lanius, R. A. (2007). Neural correlates of reexperiencing, avoidance, and dissociation in PTSD: symptom dimensions and emotion dysregulation in responses to script-driven trauma imagery. $J$. Trauma Stress 20, 713-725.

Jelsone-Swain, L. M., Fling, B. W., Seidler, R. D., Hovatter, R., Gruis, K., and Welsh, R. C. (2010). Reduced interhemispheric functional connectivity in the motor cortex during rest in limb-onset amyotrophic lateral sclerosis. Front. Syst. Neurosci. 4:158. doi:10.3389/fnsys.2010.00158

Johansen-Berg, H., Gutman, D. A., Behrens, T. E., Matthews, P. M., Rushworth, M. F., Katz, E., Lozano, A. M., and Mayberg, H. S. (2008). Anatomical connectivity of the subgenual cingulate region targeted with deep brain stimulation for treatment-resistant depression. Cereb. Cortex 18, 1374-1383.

Keane, T., Fairbank, J., Caddell, J., Zimering, R., Taylor, K., and Mora, C. (1989). Clinical evaluation of a measure to assess combat exposure. Psychol. Assess. 1, 53-55.

Kilpatrick, L., and Cahill, L. (2003). Amygdala modulation of parahippocampal and frontal regions during emotionally influenced memory storage. Neuroimage 20, 2091-2099.

Kober, H., Barrett, L. F., Joseph, J., BlissMoreau, E., Lindquist, K., and Wager, T. D. (2008). Functional grouping and cortical-subcortical interactions in emotion: a meta-analysis of neuroimaging studies. Neuroimage 42, 998-1031.

Lanius, R. A., Bluhm, R. L., Coupland, N. J., Hegadoren, K. M., Rowe, B., Theberge, J., Neufeld, R. W. Williamson, P. C., and Brimson, M. (2010). Default mode network connectivity as a predictor of posttraumatic stress disorder symptom severity in acutely traumatized subjects. Acta Psychiatr. Scand. 121, 33-40.

Lanius, R. A., Frewen, P. A., Girotti, M., Neufeld, R. W., Stevens, T. K., and Densmore, M. (2007). Neural correlates of trauma script-imagery in posttraumatic stress disorder with and without comorbid major depression: a functional MRI investigation. Psychiatry Res 155, 45-56.

Lanius, R. A., Williamson, P. C., Bluhm, R. L., Densmore, M., Boksman, K., Neufeld, R. W., Gati, J. S., and Menon, R. S. (2005). Functional connectivity of dissociative responses in posttraumatic stress disorder: a functional magnetic resonance imaging investigation. Biol. Psychiatry 57, 873-884.

Liberzon, I., and Phan, K. L. (2003). Brain-imaging studies of posttraumatic stress disorder. CNS Spectr. 8 , 641-650.

Liberzon, I., and Sripada, C. S. (2008). The functional neuroanatomy of PTSD: a critical review. Prog. Brain Res. 167, 151-169.

Liberzon, I., Taylor, S. F., Amdur, R., Jung, T. D., Chamberlain, K. R., Minoshima, S., Koeppe, R. A., and Fig, L. M. (1999). Brain activation in PTSD in response to trauma-related stimuli. Biol. Psychiatry 45, 817-826.

Lindauer, R. J., Booii, J., Habraken, J. B., Van Meijel, E. P., Uylings, H. B., Olff, M., Carlier, I. V., Den Heeten, G. J., Van Eck-Smit, B. L., and Gersons, B. P. (2008). Effects of psychotherapy on regional cerebral blood flow during trauma imagery in patients with post-traumatic stress disorder: a randomized clinical trial. Psychol. Med. 38, 543-554.

Morey, R. A., Dolcos, F., Petty, C. M., Cooper, D. A., Hayes, J. P., Labar, K. S., and Mccarthy, G. (2009). The role of trauma-related distractors on neural systems for working memory and emotion processing in posttraumatic stress disorder. J. Psychiatr. Res. 43, 809-817.
Murty, V. P., Ritchey, M., Adcock, R. A., and Labar, K. S. (2011). Reprint of: fMRI studies of successful emotional memory encoding: a quantitative meta-analysis. Neuropsychologia 49, 695-705.

Nemeroff, C. B., Bremner, J. D., Foa, E. B., Mayberg, H. S., North, C. S., and Stein, M. B. (2006). Posttraumatic stress disorder: a state-of-the-science review. J. Psychiatr. Res. 40, 1-21.

Noll, D. C., Meyer, C. H., Pauly, J. M., Nishimura, D. G., and Macovski, A. (1991). A homogeneity correction method for magnetic resonance imaging with time-varying gradients. IEEE Trans. Med. Imaging 10 629-637.

Ochsner, K. N., Bunge, S. A., Gross, J. J., and Gabrieli, J. D. (2002). Rethinking feelings: an fMRI study of the cognitive regulation of emotion. $J$. Cogn. Neurosci. 14, 1215-1229.

Osuch, E. A., Benson, B., Geraci, M., Podell, D., Herscovitch, P., Mccann, U. D., and Post, R. M. (2001). Regional cerebral blood flow correlated with flashback intensity in patients with posttraumatic stress disorder. Biol. Psychiatry 50, 246-253.

Paulus, M. P., and Stein, M. B. (2006). An insular view of anxiety. Biol. Psychiatry 60, 383-387.

Phan, K. L., Wager, T., Taylor, S. F., and Liberzon, I. (2002). Functional neuroanatomy of emotion: a metaanalysis of emotion activation studies in PET and fMRI. Neuroimage 16 331-348.

Phan, K. L., Wager, T. D., Taylor, S. F., and Liberzon, I. (2004). Functional neuroimaging studies of human emotions. CNS Spectr. 9, 258-266.

Phelps, E. A. (2004). Human emotion and memory: interactions of the amygdala and hippocampal complex. Curr. Opin. Neurobiol. 14 198-202.

Phelps, E. A., Delgado, M. R., Nearing, K. I., and Ledoux, J. E. (2004). Extinction learning in humans: role of the amygdala and vmPFC. Neuron 43, 897-905.

Pissiota, A., Frans, O., Fernandez, M., Von Knorring, L., Fischer, H., and Fredrikson, M. (2002). Neurofunctional correlates of posttraumatic stress disorder: a PET symptom provocation study. Eur. Arch. Psychiatry Clin. Neurosci. 252, 68-75.

Pitman, R. K., Shin, L. M., and Rauch, S. L. (2001). Investigating the pathogenesis of posttraumatic stress disorder with neuroimaging. J. Clin. Psychiatry 62(Suppl. 17), 47-54.

Protopopescu, X., Pan, H., Tuescher, O., Cloitre, M., Goldstein, M., Engelien, W., Epstein, J., Yang, Y., Gorman, J.,
Ledoux, J., Silbersweig, D., and Stern, E. (2005). Differential time courses and specificity of amygdala activity in posttraumatic stress disorder subjects and normal control subjects. Biol. Psychiatry 57, 464-473.

Quirk, G. J., and Mueller, D. (2008). Neural mechanisms of extinction learning and retrieval. Neuropsychopharmacology 33, 56-72.

Rauch, S. L., and Shin, L. M. (1997). Functional neuroimaging studies in posttraumatic stress disorder. Ann. N. Y. Acad. Sci. 821, 83-98.

Rauch, S. L., Shin, L. M., and Phelps, E. A. (2006). Neurocircuitry models of posttraumatic stress disorder and extinction: human neuroimaging research - past, present, and future. Biol. Psychiatry 60, 376-382.

Rauch, S. L., Shin, L. M., Whalen, P. J., and Pitman, R. K. (1998). Neuroimaging and the neuroanatomy of PTSD. CNS Spectr. 3, 30-41.

Rauch, S. L., Van Der Kolk, B. A., Fisler, R. E., Alpert, N. M., Orr, S. P., Savage, C. R., Fischman, A. J., Jenike, M. A., and Pitman, R. K. (1996). A symptom provocation study of posttraumatic stress disorder using positron emission tomography and script-driven imagery. Arch. Gen. Psychiatry 53, 380-387.

Rauch, S. L., Whalen, P. J., Shin, L. M., Mcinerney, S. C., Macklin, M. L., Lasko, N. B., Orr, S. P., and Pitman, R. K. (2000). Exaggerated amygdala response to masked facial stimuli in posttraumatic stress disorder: a functional MRI study. Biol. Psychiatry 47, 769-776.

Ritchey, M., Dolcos, F., and Cabeza, R. (2008). Role of amygdala connectivity in the persistence of emotional memories over time: an eventrelated fMRI investigation. Cereb. Cortex 18, 2494-2504.

Roy, A. K., Shehzad, Z., Margulies, D. S., Kelly, A. M., Uddin, L. Q., Gotimer, K., Biswal, B. B., Castellanos, F. X., and Milham, M. P. (2009). Functional connectivity of the human amygdala using resting state fMRI. Neuroimage 45, 614-626.

Saunders, R. C., Rosene, D. L., and Van Hoesen, G. W. (1988). Comparison of the efferents of the amygdala and the hippocampal formation in the rhesus monkey: II. Reciprocal and non-reciprocal connections. $J$. Comp. Neurol. 271, 185-207.

Shaw, M. E., Moores, K. A., Clark, R. C., Mcfarlane, A. C., Strother, S. C., Bryant, R. A., Brown, G. C., and Taylor, J. D. (2009). Functional connectivity reveals inefficient working memory systems in post-traumatic stress disorder. Psychiatry Res 172, 235-241. 
Shin, L. M. (2009). "The amygdala in post-traumatic stress disorder," in Post-Traumatic Stress Disorder: Basic Science and Clinical Practice, eds P. J. Shiromani, T. M. Keane, and J. E. Le Doux (New York: Humana Press), 319-334.

Shin, L. M., Kosslyn, S. M., Mcnally, R. J., Alpert, N. M., Thompson, W. L., Rauch, S. L., Macklin, M. L., and Pitman, R. K. (1997). Visual imagery and perception in posttraumatic stress disorder. A positron emission tomographic investigation. Arch. Gen. Psychiatry 54, 233-241.

Shin, L. M., and Liberzon, I. (2010). The neurocircuitry of fear, stress, and anxiety disorders. Neuropsychopharmacology 35, 169-191.

Shin, L. M., Orr, S. P., Carson, M. A., Rauch, S. L., Macklin, M. L., Lasko, N. B., Peters, P. M., Metzger, L. J., Dougherty, D. D., Cannistraro, P. A., Alpert, N. M., Fischman, A. J., and Pitman, R. K. (2004a). Regional cerebral blood flow in the amygdala and medial prefrontal cortex during traumatic imagery in male and female Vietnam veterans with PTSD. Arch. Gen. Psychiatry 61, 168-176.

Shin, L. M., Shin, P. S., Heckers, S., Krangel, T. S., Macklin, M. L., Orr, S. P., Lasko, N., Segal, E., Makris, N., Richert, K., Levering, J., Schacter, D. L., Alpert, N. M., Fischman, A. J., Pitman, R. K., and Rauch, S. L. (2004b). Hippocampal function in posttraumatic stress disorder. Hippocampus 14, 292-300.

Shin, L. M., Rauch, S. L., and Pitman, R. K. (2006). Amygdala, medial prefrontal cortex, and hippocampal function in PTSD. Ann. N. Y. Acad. Sci. 1071, 67-79.

Shin, L. M., Wright, C. I., Cannistraro, P. A., Wedig, M. M., Mcmullin, K., Martis, B., Macklin, M. L., Lasko, N. B., Cavanagh, S. R., Krangel, T. S., Orr, S. P., Pitman, R. K., Whalen, P. J., and Rauch, S. L. (2005). A functional magnetic resonance imaging study of amygdala and medial prefrontal cortex responses to overtly presented fearful faces in posttraumatic stress disorder. Arch. Gen. Psychiatry 62, 273-281.

Simmons, A., Matthews, S. C., Stein, M. B., and Paulus, M. P. (2004). Anticipation of emotionally aversive visual stimuli activates right insula. Neuroreport 15, 2261-2265.
Simmons, A., Strigo, I., Matthews, S. C., Paulus, M. P., and Stein, M. B. (2006). Anticipation of aversive visual stimuli is associated with increased insula activation in anxiety-prone subjects. Biol. Psychiatry 60, 402-409.

Simmons, A. N., Paulus, M. P., Thorp, S. R., Matthews, S. C., Norman, S. B., and Stein, M. B. (2008). Functional activation and neural networks in women with posttraumatic stress disorder related to intimate partner violence. Biol. Psychiatry 64, 681-690.

Stefanacci, L., Suzuki, W. A., and Amaral, D. G. (1996). Organization of connections between the amygdaloid complex and the perirhinal and parahippocampal cortices in macaque monkeys. J. Comp. Neurol. $375,552-582$.

Stein, J. L., Wiedholz, L. M., Bassett, D. S., Weinberger, D. R., Zink, C. F., Mattay, V.S., and Meyer-Lindenberg, A. (2007a). A validated network of effective amygdala connectivity. Neuroimage 36, 736-745.

Stein, M. B., Simmons, A. N., Feinstein, J. S., and Paulus, M. P. (2007b). Increased amygdala and insula activation during emotion processing in anxiety-prone subjects. Am. J. Psychiatry 164, 318-327.

Stenger, V. A., Boada, F. E., and Noll, D. C. (2000). Three-dimensional tailored RF pulses for the reduction of susceptibility artifacts in $\mathrm{T}\left({ }^{*}\right)(2)$ weighted functional MRI. Magn. Reson. Med. 44, 525-531.

Taylor, S. F., Phan, K. L., Decker, L. R., and Liberzon, I. (2003). Subjective rating of emotionally salient stimuli modulates neural activity. Neuroimage 18, 650-659.

Tzourio-Mazoyer, N., Landeau, B., Papathanassiou, D., Crivello, F., Etard, O., Delcroix, N., Mazoyer, B., and Joliot, M. (2002). Automated anatomical labeling of activations in SPM using a macroscopic anatomical parcellation of the MNI MRI single-subject brain. Neuroimage 15, 273-289.

Urry, H. L., Van Reekum, C. M., Johnstone, T., Kalin, N. H., Thurow, M. E., Schaefer, H. S., Jackson, C. A., Frye, C. J., Greischar, L. L., Alexander, A. L., and Davidson, R. J. (2006). Amygdala and ventromedial prefrontal cortex are inversely coupled during regulation of negative affect and predict the diurnal pattern of cortisol secretion among older adults. $J$. Neurosci. 26, 4415-4425.

van den Heuvel, M. P., Mandl, R. C., Kahn, R. S., and Hulshoff Pol, H. E. (2009). Functionally linked restingstate networks reflect the underlying structural connectivity architecture of the human brain. Hum. Brain Mapp. 30, 3127-3141.

Vermetten, E., Schmahl, C., Southwick, S. M., and Bremner, J. D. (2007). Positron tomographic emission study of olfactory induced emotional recall in veterans with and without combat-related posttraumatic stress disorder. Psychopharmacol. Bull. 40, 8-30.

Wager, T. D., Davidson, M. L., Hughes, B. L., Lindquist, M. A., and Ochsner, K. N. (2008). Prefrontalsubcortical pathways mediating successful emotion regulation. Neuron 59, 1037-1050.

Wager, T. D., Phan, K. L., Liberzon, I., and Taylor, S. F. (2003). Valence, gender, and lateralization of functional brain anatomy in emotion: a meta-analysis of findings from neuroimaging. Neuroimage 19, 513-531.

Walter, B., Blecker, C., Kirsch, P., Sammer, G., Schienle, A., Stark, R., and Vaitl, D. (2003). "MARINA: an easy tool for the creation for MAsks for Region of INterest Analyses," in 9th International Conference on Functional Mapping of the Human Brain: NeuroImage.

Welsh, R. C., Rahbar, H., Foerster, B., Thurnher, M., and Sundgren, P. C. (2007). Brain diffusivity in patients with neuropsychiatric systemic lupus erythematosus with new acute neurological symptoms. J. Magn. Reson. Imaging 26, 541-551.

Werner, N. S., Meindl, T., Engel, R. R., Rosner, R., Riedel, M., Reiser, M. and Fast, K. (2009). Hippocampal function during associative learning in patients with posttraumatic stress disorder. J. Psychiatr. Res. 43, 309-318.

Whalley, M. G., Rugg, M. D., Smith, A. P., Dolan, R. J., and Brewin, C. R. (2009). Incidental retrieval of emotional contexts in post-traumatic stress disorder and depression: an fMRI study. Brain Cogn. 69, 98-107.
Williams, J. B. (1988). A structured interview guide for the Hamilton Depression Rating Scale. Arch. Gen. Psychiatry 45, 742-747.

Williams, L. M., Kemp, A. H., Felmingham, K., Barton, M., Olivieri, G., Peduto, A., Gordon, E., and Bryant, R. A. (2006). Trauma modulates amygdala and medial prefrontal responses to consciously attended fear. Neuroimage 29, 347-357.

Yin, Y., Jin, C., Hu, X., Duan, L., Li, Z., Song, M., Chen, H., Feng, B., Jiang, T., Jin, H., Wong, C., Gong, Q., and Li, L. (2011a). Altered resting-state functional connectivity of thalamus in earthquakeinduced posttraumatic stress disorder: a functional magnetic resonance imaging study. Brain Res. 1411, 98-107.

Yin, Y., Li, L., Jin, C., Hu, X., Duan, L., Eyler, L. T., Gong, Q., Song, M., Jiang, T., Liao, M., Zhang, Y., and Li, W. (2011b). Abnormal baseline brain activity in posttraumatic stress disorder: a restingstate functional magnetic resonance imaging study. Neurosci. Lett. 498, 185-189.

Conflict of Interest Statement: The authors declare that the research was conducted in the absence of any commercial or financial relationships that could be construed as a potential conflict of interest.

Received: 30 September 2011; accepted: 28 October 2011; published online: 14 November 2011.

Citation: Rabinak CA, Angstadt $M$, Welsh RC, Kenndy AE, Lyubkin M, Martis B and Phan KL (2011) Altered amygdala resting-state functional connectivity in post-traumatic stress disorder. Front. Psychiatry 2:62. doi: 10.3389/fpsyt.2011.00062

This article was submitted to Frontiers in Neuropsychiatric Imaging and Stimulation, a specialty of Frontiers in Psychiatry. Copyright (C) 2011 Rabinak, Angstadt, Welsh, Kenndy, Lyubkin, Martis and Phan. This is an open-access article subject to a non-exclusive license between the authors and Frontiers Media SA, which permits use, distribution and reproduction in other forums, provided the original authors and source are credited and other Frontiers conditions are complied with. 